\title{
Hematological indices as simple, inexpensive and practical severity markers of obstructive sleep apnea syndrome: a meta-analysis
}

\author{
Mindan $\mathrm{Wu}^{1}$, Lingren $\mathrm{Zhou}^{1}$, Ding Zhu ${ }^{1}$, Tianwen Lai ${ }^{1,2}$, Zhihua Chen ${ }^{1}$, Huahao Shen ${ }^{1,3}$ \\ ${ }^{1}$ Key Laboratory of Respiratory Disease of Zhejiang Province, Department of Respiratory and Critical Care Medicine, Second Affiliated Hospital \\ of Zhejiang University School of Medicine, Hangzhou 310009, China; ${ }^{2}$ Department of Respiratory and Critical Care Medicine, Affiliated Hospital, \\ Institute of Respiratory Diseases, Guangdong Medical University, Zhanjiang 524000, China; ${ }^{3}$ State Key Lab. for Respiratory Diseases, Guangzhou \\ 510120, China \\ Contributions: (I) Conception and design: $M$ Wu, T Lai; (II) Administrative support: H Shen, Z Chen; (III) Provision of study materials: $M$ Wu, \\ D Zhu; (IV) Collection and assembly of data: M Wu, L Zhou; (V) Data analysis and interpretation: M Wu, L Zhou; (VI) Manuscript writing: All \\ authors; (VII) Final approval of the manuscript: All authors. \\ Correspondence to: Huahao Shen. Key Laboratory of Respiratory Disease of Zhejiang Province, Department of Respiratory and Critical Care \\ Medicine, Second Affiliated Hospital of Zhejiang University School of Medicine, 88 Jiefang Road, Hangzhou 310009, China. \\ Email: huahaoshen@zju.edu.cn.
}

Background: Clinical detection of inflammatory markers is useful to assess the degree of nocturnal hypoxia and predict the presence of complications in obstructive sleep apnea syndrome (OSAS) patients. Nowadays, some researchers proposed that hematological parameters could be substituted for novel diseasespecific biochemical markers (such as C-reactive protein) because they were comparatively cheap, simple and practical. But there was a contradiction whether the hematological parameters were positively correlated with the OSAS severity.

Methods: Medical databases were searched included PubMed, Web of Science, Scopus, Cochrane Library, Clinical Trial, Embase and Google Scholar (up to March 29, 2018). We used weighted mean differences (WMDs) with 95\% confidence intervals (CIs) from random-effects model.

Results: Seventeen studies were included in this meta-analysis and results were presented by different hematological parameters. Pooled analysis showed that OSAS was associated with a high level of WBC (white blood cell, 11 studies, 2,206 subjects, WMD: 0.58; 95\% CI: 0.31 to 0.85; P<0.0001), NLR (neutrophil-tolymphocyte ratio, 5 studies, 1416 subjects, WMD: 0.46; 95\% CI: 0.13 to $0.80 ; \mathrm{P}=0.007$ ), MPV (mean platelet volume, 8 studies, 1,854 subjects, WMD: 0.63 ; 95\% CI: 0.29 to $0.98 ; \mathrm{P}=0.0004$ ), PDW (platelet distribution width, 6 studies, 1,911 subjects, WMD: 0.76; 95\% CI: 0.47 to 1.06; $\mathrm{P}<0.00001$ ), PLR (platelet-to-lymphocyte ratio, 3 studies, 998 subjects, WMD: 21.76; 95\% CI: 8.54 to 34.99; $\mathrm{P}=0.001$ ), RDW (red cell distribution width, 5 studies, 1,701 subjects, WMD: 0.31 ; 95\% CI: 0.11 to $0.51 ; \mathrm{P}=0.002$ ) and HCT (hematocrit, 3 studies, 662 subjects, WMD: 1.58; 95\% CI: 0.52 to 2.64; $\mathrm{P}=0.003)$. But OSAS was associated with a low level of LYM (lymphocyte, 5 studies, 1,285 subjects, WMD: $-0.27 ; 95 \%$ CI: -0.49 to $-0.06 ; \mathrm{P}=0.01$ ). There was a gradual rising trend from mild OSAS to severe OSAS existed in all subgroups.

Conclusions: Hematological indices are comparatively Simple, Inexpensive and Practical Severity Markers of OSAS including WBC, LYM, NLR, MPV, PDW, PLR, RDW and HCT.

Keywords: Hematological indices; meta-analysis; obstructive sleep apnea syndrome (OSAS); severity; biomarker

Submitted Apr 02, 2018. Accepted for publication Sep 13, 2018.

doi: $10.21037 /$ jtd.2018.10.105

View this article at: http://dx.doi.org/10.21037/jtd.2018.10.105

(c) Journal of Thoracic Disease. All rights reserved. 


\section{Introduction}

Obstructive sleep apnea syndrome (OSAS) is a common disease with a prevalence of moderate to severe sleep apnea in $6 \%$ to $13 \%$ of the adults population which affecting more than 20 million Americans (1). It is characterized by recurrent obstruction of partial or total upper airway and subsequent paroxysmal nocturnal hypoxia which leads to intermittent arousals from sleep, excessive daytime sleepiness and so on (2).

Although the etiologies and pathophysiological mechanisms are still not thoroughly understood, OSAS can lead to some complications such as cardiovascular disorders (CVDs), cancer and diabetes (3). And CVD occupies a large part in complications (4-6). Several evidences proposed that the predisposition to CVD of OSAS patients may be associated with endothelial dysfunction, excessive oxidative stress, increased systemic inflammation and sympathetic excitation (7-11).

The chronic systematic inflammation of OSAS may play an important role in the progression of CVD (12). Recent studies suggest that both WBC and NLR are good indicators of inflammation (13-17). Neutrophils (NEU) mainly mediate innate immune response by secreting mediators while LYM mediate adaptive immune response by regulating inflammation (18). Besides, some studies reported platelet was activated and aggregated in patients with OSAS, which was also relevant in inflammation $(19,20)$. MPV and PDW are both useful markers of platelet activity. Recently, studies introduce PLR as a novel inflammatory marker to predict the adverse outcomes of CVD $(14-17,21)$. Third, in view of hypoxemic states, HCT was elevated in OSAS patients that might be called secondary erythrocytosis (22). What's more, red cell distribution width (RDW), which assessed the variability of erythrocyte, was also reported to be increased in relation to inflammation in OSAS (23).

Clinical detection of inflammatory markers is useful to assess the degree of nocturnal hypoxia and predict the presence of complications in OSAS patients. Nowadays, clinical scientists usually use the novel disease-specific biochemical markers to measure the overall inflammatory status of human body. However, there is an obvious drawback that such markers, such as C-reactive protein and interleukin-6, are always expensive and time-consuming, especially in developing countries. Besides, blood routine examination is used more frequently than disease-specific biochemical markers in primary hospital. Hence, we proposed the hematological parameters mentioned above could be alternative markers to evaluate the inflammation in OSAS population because they were comparatively cheap, readily-measurable, easy and practical laboratory markers.

Nevertheless, there was a contradiction whether the hematological parameters were positively correlated with the OSAS severity. Therefore, we conducted the metaanalysis to solve this problem and assessed the values of hematological indices to be Severity Markers of OSAS. To the best of our knowledge, this is the first meta-analysis in this academic field.

\section{Methods}

Our study was performed according to The Preferred Reporting Items for Systematic Reviews and Meta-Analysis (PRISMA) guidelines (24).

\section{Data sources and search strategy}

Medical databases were searched included PubMed, Web of Science, Scopus, Cochrane Library, Clinical Trial, Embase and Google Scholar. Each database was searched from inception through March 29, 2018. The following terms were used in the search: ("hematology" or "white blood cell count" or "neutrophil count" or "lymphocyte count" or "neutrophil-to-lymphocyte ratio" or "NLR" or "platelet count" or "platelet-to-lymphocyte ratio" or "PLR" or "mean platelet volume" or "MPV" or "platelet distribution width" or "PDW" or "red cell count" or "Hematocrit" or "HCT" or "red cell distribution width" or "RDW") and ("obstructive sleep apnea syndrome" or "OSAS"). Meanwhile, we scanned the reference list of included studies and relevant scientific meetings.

\section{Selection criteria}

Inclusion criteria for this meta-analysis: (I) patients: adults who had OSAS and were categorized into three OSAS severity groups as mild, moderate and severe according to the apnea-hypopnea index (AHI) values of 5-14, 15-29 and more than 30, respectively (25); (II) outcomes: clinical hematological parameters including white blood cell, neutrophil, lymphocyte, neutrophil-to-lymphocyte ratio, platelet, platelet-to-lymphocyte ratio, mean platelet volume, platelet distribution width, erythrocyte, hematocrit and RDW; (III) study language: only English language; (IV) data: 
all the data was based on means and standard deviations or medians and ranges.

Exclusion criteria: studies didn't have available data and control group.

\section{Quality assessment}

Two reviewers ( $\mathrm{M} \mathrm{Wu}$ and $\mathrm{L}$ Zhou) used the Effective Public Health Practice Project tool (EPHPP) (26) to assess the methodological quality of included studies in this review. We graded key component assessments as strong, moderate, or weak: Selection bias, Study design, Data collection methods and Confounders. From the component-specific assessments, we derived an overall quality assessment according to each component assessment of no weak rating, one weak rating and two or more weak ratings. Any discrepancies were resolved by discussion or a third reviewer.

\section{Data extraction}

Two authors (M Wu and L Zhou) independently evaluated all the studies that were retrieved from the databases and bibliography and determined the final included studies according to inclusion criteria described above. Any disagreements were resolved via consensus or third reviewer when necessary. For each included study, we extracted data using two data extraction forms.

\section{Statistical analysis}

We used weighted mean differences (WMDs) with 95\% confidence intervals (95\% CIs) for the meta-analysis to analyze the association between hematological parameters and OSAS severity. The $\mathrm{I}^{2}$ statistic was used to assess the heterogeneity across the studies. Heterogeneity was defined as low, moderate and high heterogeneity according to $\mathrm{I}^{2}$ statistic values of $25 \%, 50 \%$ and $75 \%$. When heterogeneity was found, we performed a sensitivity analysis to determine which studies contributed most significantly to the heterogeneity. The respiratory disturbance index (RDI) was combined data with AHI. If a study only reported median (Q25-Q75), then the data was calculates as an estimate of mean and SD according to the Cochrane Handbook (27). The Egger's test and Begg's test were used to assess publication bias. All analyses were performed with Review Manager (Version 5.3, The Cochrane Collaboration) and Stata (Version SE12.0, Stata Corporation, USA). A P value of $<0.05$ was considered to be statistically significant.

\section{Results}

\section{Studies identification and characteristic}

A total of 2,479 studies were identified from searching the electronic database. After screening, 35 studies were full-text reviewed for eligibility. Finally 17 studies $(19,20,22,23,28-40)$ met the inclusion criteria and were included in this metaanalysis. The detailed steps of the study identification process are shown in Figure 1. The characteristic of each study were summarized in Table 1 and Table S1. Table 1 mainly included general characteristics: author, year, country, outcomes, characteristic of OSAS patients and quality assessment. Table $S 1$ presented the demographic data: total sample size of each eligible study, detailed demographic data of each severity group (AHI, sample size, age, BMI and male proportion). The methodological quality was assessed according to the EPHPP tool (Table S2).

\section{Results of meta-analysis}

A total of 4,518 cases were selected from 17 studies, of which 1,013 were control subjects, 896 were mild OSAS subjects, 832 were moderate OSAS subjects and 1,588 were severe OSAS subjects. In terms of different hematological indices, we made eight subgroup meta-analyses. We analyzed WBC, lymphocyte, NLR, MPV, PDW, PLR, RDW and HCT of the mild, moderate and severe OSAS group versus control group respectively. Figures 2-4 were generated by Stata and the detail values were reconfirmed by Review Manager. Figures from Stata only provided WMDs and 95\% CIs, therefore the P values of WMDs showed in the following results were provided by Review Manager (not showed in the figures).

\section{$W B C$}

A total of 2,206 subjects were enrolled from 11 studies $(20,22,30,32-34,36-38,40,41)$, of which 421 were allocated to the mild OSAS group, 448 to the moderate OSAS group, 805 to the severe OSAS group and 532 to the control group. Mean WBC counts were 6.874, 7.159, 6.968 and $7.586\left(\times 10^{9} / \mathrm{L}\right)$ in control, mild, moderate and severe OSAS groups (Table S3). Total pooled analysis result showed that OSAS was associated with a higher level of WBC (WMD: 


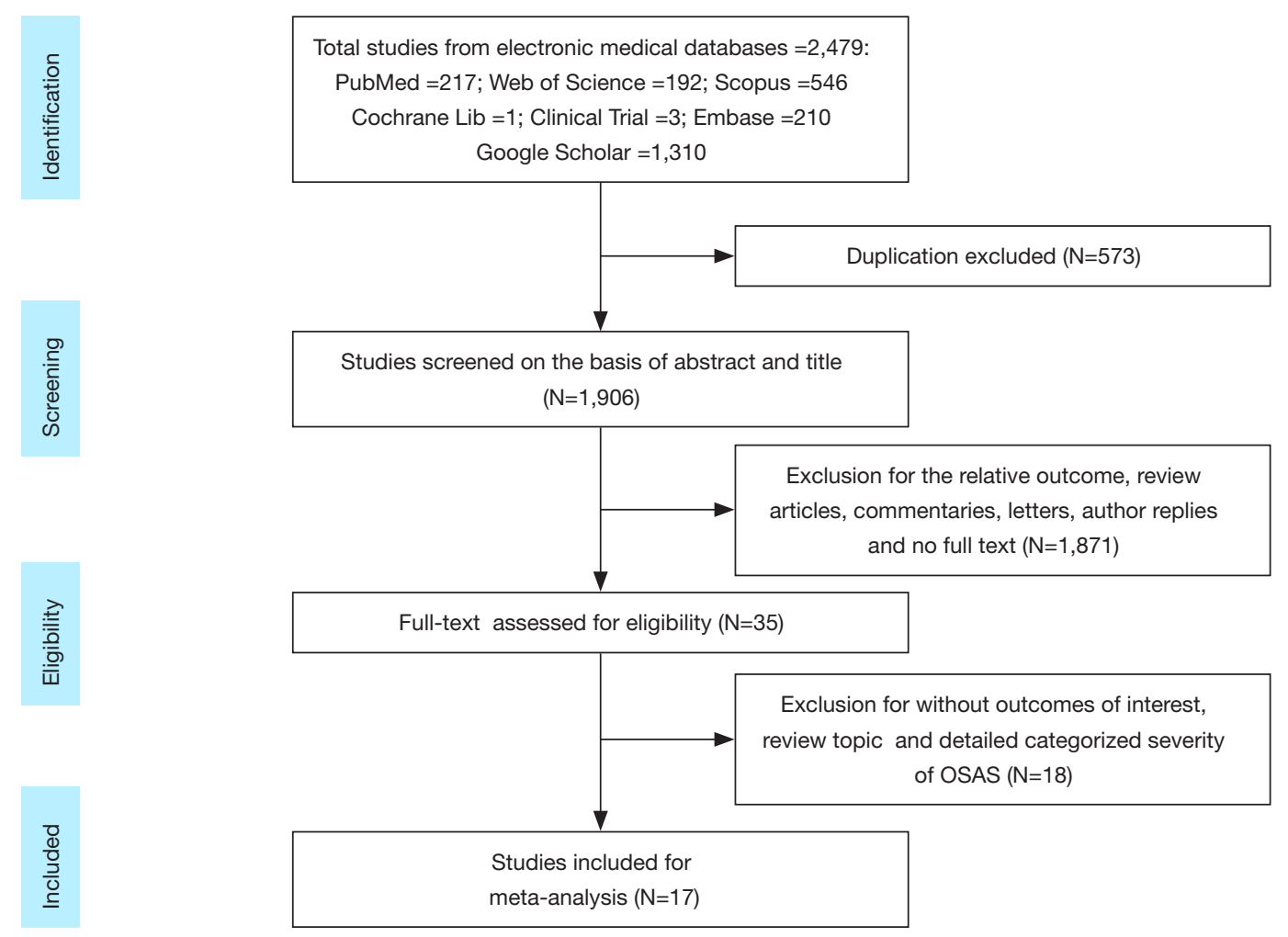

Figure 1 Flow diagram.

0.58; 95\% CI: 0.31 to $0.85 ; \mathrm{P}<0.0001)$. And increased WBC counts of severe OSAS (WMD $=0.79,95 \%$ CI: 0.35 to 1.23 , $\mathrm{P}=0.0005$ ) was little higher than the mild OSAS (WMD $=0.52,95 \%$ CI: 0.10 to $0.94, \mathrm{P}=0.01)$. All of them showed high heterogeneity: $\mathrm{I}^{2}=87.3 \%$ and $78.4 \%$ respectively (Figure 2A).

\section{$L Y M$}

A total of 1,285 subjects were included from 5 studies (30-32,37,40), of which 278 were enrolled in the mild OSAS group, 263 to the moderate OSAS group, 430 to the severe OSAS group and 314 to the control group. Mean lymphocyte counts were $2.714,2.666,2.419$ and 2.222 $\left(\times 10^{9} / \mathrm{L}\right)$ in control, mild, moderate and severe OSAS group (Table S3). Total pooled analysis result suggested that OSAS was associated with a lower level of LYM (WMD: -0.27 ; 95\% CI: -0.49 to $-0.06 ; \mathrm{P}=0.01)$. And lymphocyte counts gradually decreased with regard of OSAS severity and it was statistically significant until it developed to severe OSAS $(\mathrm{WMD}=-0.49,95 \% \mathrm{CI}:-0.88$ to $-0.09, \mathrm{P}=0.02)$. But a considerable heterogeneity was observed among the severe
OSAS groups $\left(\mathrm{I}^{2}=90.2 \%, \mathrm{P}=0.000\right)$ (Figure $\left.2 B\right)$.

\section{$N L R$}

A total of 1,416 subjects were selected from 5 studies (30-32,36,37), of which 348 were assigned to the mild OSAS group, 339 to the moderate OSAS group, 405 to the severe OSAS group and 324 to the control group. Mean neutrophil-to-lymphocyte ratios were 1.769, 1.874, 2.17 and 2.676 in control, mild, moderate and severe OSAS groups (Table S3). Total pooled analysis result showed that OSAS was associated with a higher level of NLR (WMD: $0.46 ; 95 \%$ CI: 0.13 to $0.80 ; \mathrm{P}=0.007)$. And there was a gradual rising trend from mild OSAS to severe OSAS which ultimately significant increased (WMD $=0.90,95 \% \mathrm{CI}$ : 0.04 to $1.76, \mathrm{P}=0.04$ ) but was with significant heterogeneity $\left(\mathrm{I}^{2}=98.3 \%, \mathrm{P}=0.000\right)$ (Figure $2 C$ ).

\section{$M P V$}

A total of 1,854 patients were included from 8 studies $(19,20,31,32,35,38-40)$, of which 354 were recruited in the 
Table 1 General characteristics of included studies

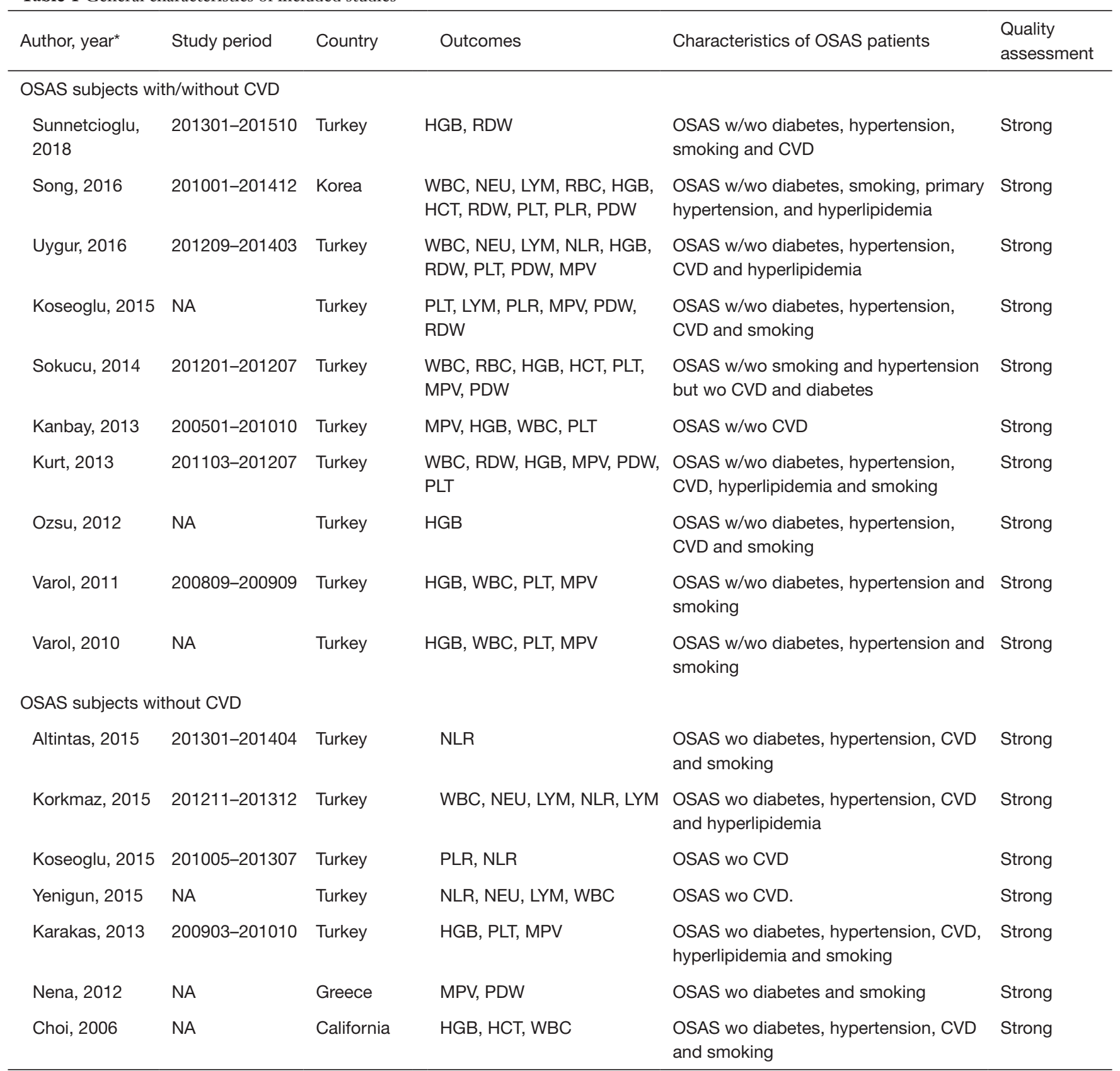

*, all studies were retrospective case series. WBC, white blood cell; LYM, lymphocyte; NEU, neutrophil; NLR, neutrophil-to-lymphocyte ratio; RBC, red blood cell; PLT, platelet; PLR, platelet-to-lymphocyte ratio; HGB, hemoglobin; HCT, hematocrit; RDW, red cell distribution width; MPV, mean platelet volume; PDW, platelet distribution width; CVD, cardiovascular disease; COPD, chronic obstructive pulmonary disease; w/o, without; w/wo, with and without.

mild OSAS group, 319 to the moderate OSAS group, 728 to the severe OSAS group and 453 to the control group. The average volumes of mean platelet volumes were 8.256, 8.553, 8.851 and $9.196 \mathrm{fL}$ in control, mild, moderate and severe OSAS groups (Table S3). Total pooled analysis result showed that OSAS was associated with a higher level of MPV (WMD: 0.63; 95\% CI: 0.29 to $0.98 ; \mathrm{P}=0.0004$ ). And we could observe a gradual increasing trend with the 

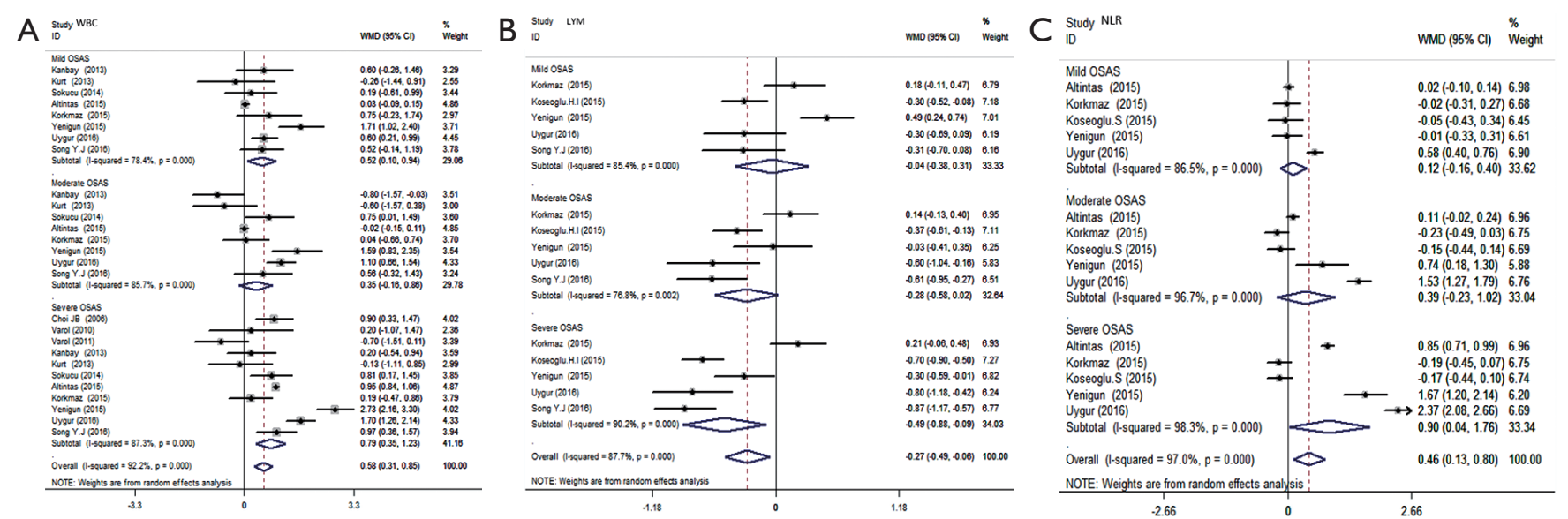

Figure 2 Forest plots of the relationship between inflammatory associated indices (WBC, LYM and NLR) and severity groups of OSAS versus control. OSAS, obstructive sleep apnea syndrome; WBC, white blood cell; LYM, lymphocyte; NLR, neutrophil-to-lymphocyte ratio.
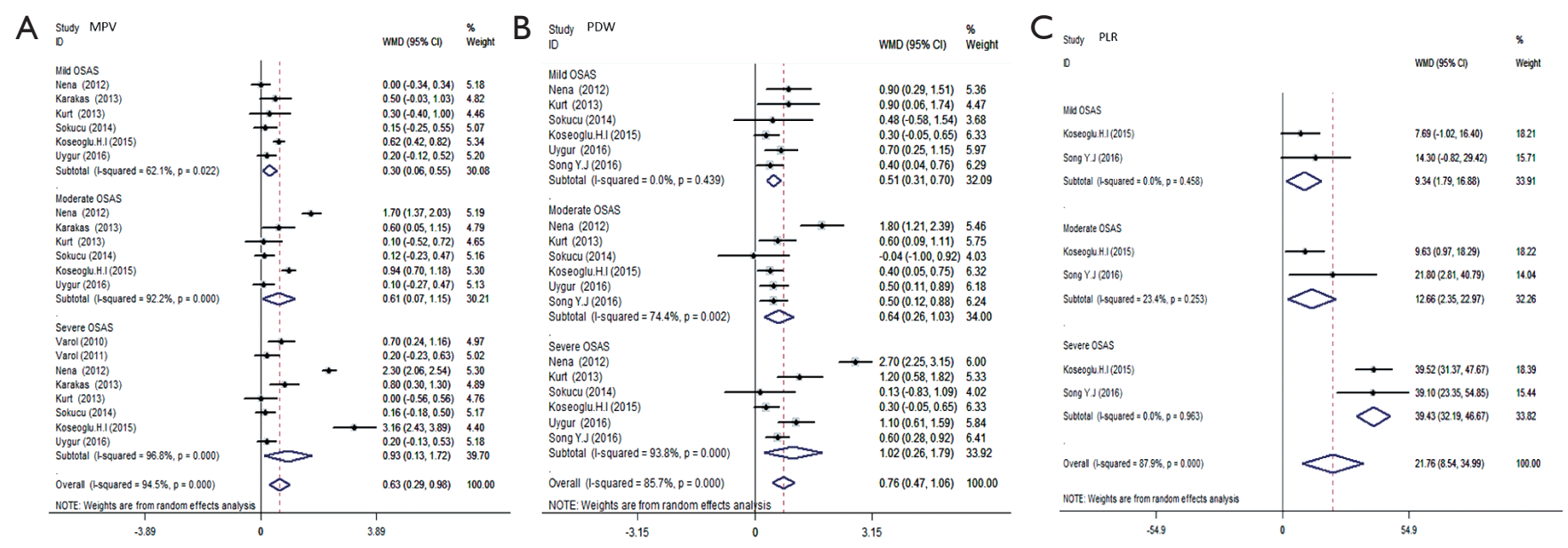

Figure 3 Forest plots of the relationship between platelet associated indices (MPV, PDW and PLR) and severity groups of OSAS versus control. OSAS, obstructive sleep apnea syndrome; MPV, mean platelet volume; PDW, platelet distribution width; PLR, platelet-tolymphocyte ratio.

development of OSAS severity. The severe OSAS group (WMD $=0.93,95 \%$ CI: 0.13 to $1.72, \mathrm{P}=0.02$ ) increased more than mild OSAS (WMD $=0.30,95 \%$ CI: 0.06 to $0.55, \mathrm{P}=0.02$ ) and moderate OSAS groups (WMD $=0.61,95 \% \mathrm{CI}: 0.07$ to $1.15, \mathrm{P}=0.03)$. However, the moderate $\left(\mathrm{I}^{2}=92.2 \%, \mathrm{P}=0.000\right)$ and severe OSAS groups $\left(\mathrm{I}^{2}=96.8 \%, \mathrm{P}=0.000\right)$ had remarkable heterogeneity while mild OSAS group had moderate heterogeneity $\left(\mathrm{I}^{2}=62.1 \%, \mathrm{P}=0.022\right)$ (Figure $\left.3 A\right)$.

\section{PDW}

A total of 1,911 subjects were enrolled from 6 studies
(19,30-32,40,41), of which 391 were allocated to the mild OSAS group, 348 to the moderate OSAS group, 738 to the severe OSAS group and 434 to the control group. Mean platelet distribution widths were $14.818 \%, 15.431 \%$, $15.445 \%$ and $15.823 \%$ in control, mild, moderate and severe OSAS groups (Table S3). Total pooled analysis result showed that OSAS was associated with a higher level of PDW (WMD: 0.76; 95\% CI: 0.47 to 1.06 ; $<<0.00001$ ). And the evaluated PDW of severe OSAS (WMD $=1.02$, $95 \%$ CI: 0.26 to $1.79, \mathrm{P}=0.008)$ was much higher than the moderate OSAS (WMD $=0.64,95 \%$ CI: 0.26 to 1.03 , $\mathrm{P}=0.001)$ and mild OSAS group (WMD $=0.51,95 \%$ CI: 

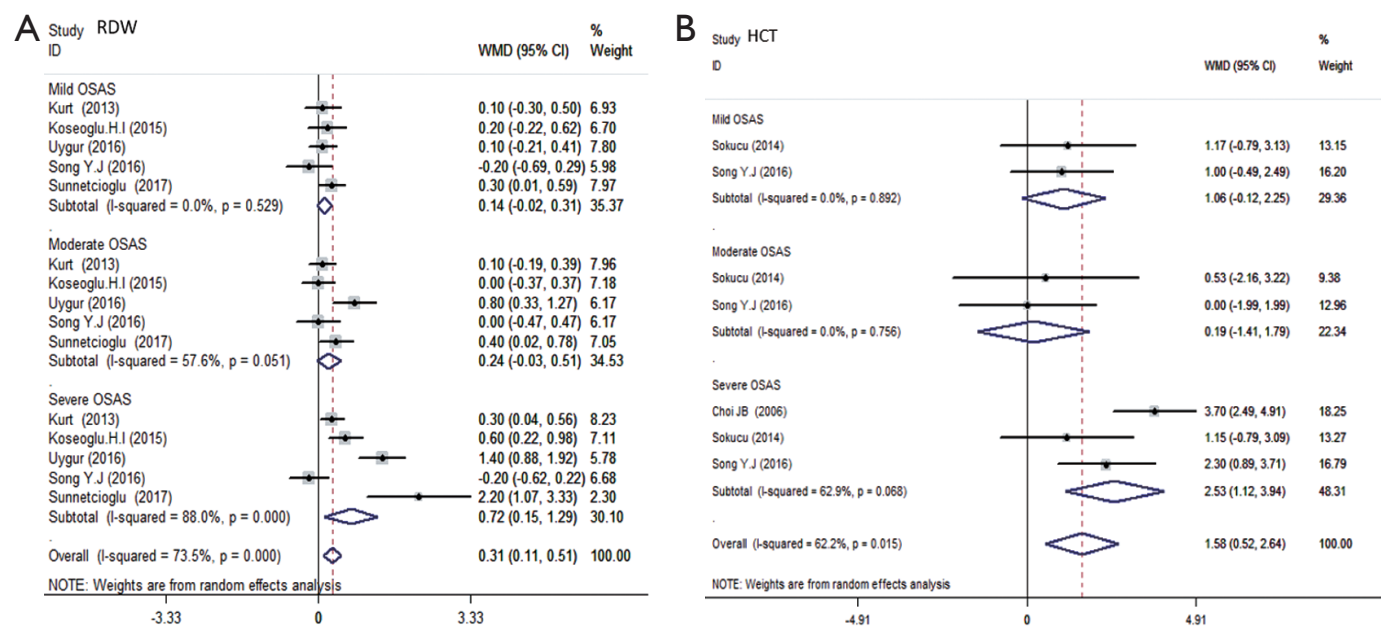

Figure 4 Forest plots of the relationship between erythrocyte associated indices (RDW and HCT) and severity groups of OSAS versus control. OSAS, obstructive sleep apnea syndrome; RDW, red cell distribution width; HCT, hematocrit.

0.31 to $0.70, \mathrm{P}<0.00001)$. However, the moderate $\left(\mathrm{I}^{2}=74.4 \%\right.$, $\mathrm{P}=0.002)$ and severe OSAS groups $\left(\mathrm{I}^{2}=93.8 \%, \mathrm{P}=0.000\right)$ had remarkable heterogeneity while mild OSAS group didn't have heterogeneity $\left(\mathrm{I}^{2}=0 \%, \mathrm{P}=0.439\right)$ (Figure 3B).

\section{PLR}

A total of 998 subjects were selected from 3 studies $(28,30,31)$, of which 227 were recruited in the mild OSAS group, 204 to the moderate OSAS group, 401 to the severe OSAS group and 166 to the control group. In this subgroup, we first enrolled all eligible studies into metaanalysis but the results showed a significant heterogeneity, but when we excluded Koseoglu (28), there were no heterogeneity among mild and severe OSAS group and low heterogeneity among moderate OSAS group (details in Table S3). The mean platelet-to-lymphocyte ratios of final included studies were 103.61, 107.09, 110.63 and 123.63 in control, mild, moderate and severe OSAS groups (Table S3). The final total pooled analysis result showed that OSAS was associated with a higher level of PLR (WMD: 21.76; 95\% CI: 8.54 to $34.99 ; \mathrm{P}=0.001)$. And there was a gradual rising trend from mild OSAS (WMD $=9.34,95 \%$ CI: 1.79 to $16.88, \mathrm{P}=0.02$ ), moderate OSAS (WMD $=12.66,95 \% \mathrm{CI}$ : 2.35 to $22.97, \mathrm{P}=0.02$ ) to severe OSAS (WMD $=39.43,95 \%$ CI: 32.19 to $46.67, \mathrm{P}<0.00001)$. And moderate OSAS group $\left(I^{2}=23.4 \%, P=0.253\right)$ had low heterogeneity while mild and moderate OSAS group didn't have heterogeneity $\left(\mathrm{I}^{2}=0.0 \%\right)$ (Figure 3C).

\section{$R D W$}

A total of 1,701 subjects were enrolled from 5 studies (29-32,40), of which 381 were allocated to the mild OSAS group, 320 to the moderate OSAS group, 547 to the severe OSAS group and 453 to the control group. Mean RDWs were $14.46 \%, 14.56 \%, 14.72 \%$ and $15.32 \%$ in control, mild, moderate and severe OSAS groups (Table S3). The total pooled analysis result showed that OSAS was associated with a higher level of RDW (WMD: $0.31 ; 95 \%$ CI: 0.11 to $0.51 ; \mathrm{P}=0.002)$. And there was a gradual rising trend from mild OSAS (WMD $=0.14,95 \%$ CI: -0.02 to $0.31, \mathrm{P}=0.08)$ to severe OSAS which ultimately significant increased (WMD $=0.72,95 \%$ CI: 0.15 to 1.29 , $\mathrm{P}=0.01)$ but was with considerable heterogeneity $\left(\mathrm{I}^{2}=88.0 \%\right.$, $\mathrm{P}=0.000$ ) (Figure 4A).

\section{HCT}

A total of 662 subjects were included from 3 studies (22,30,35), of whom 105 were assigned to the mild OSAS group, 102 to the moderate OSAS group, 303 to the severe OSAS group and 152 to the control group. Mean hematocrits were $41.25 \%$, 43.07\%, $42.25 \%$ and $43.64 \%$ in control, mild, moderate and severe OSAS groups (Table S3). The total pooled analysis result showed that OSAS was associated with a higher level of HCT (WMD: 1.58; $95 \%$ CI: 0.52 to $2.64 ; \mathrm{P}=0.003)$. And the values of HCT evaluated and reached a statistical significant increase 
until it was severe in OSAS group (WMD $=2.53,95 \%$ CI: 1.12 to $3.94, \mathrm{P}=0.0004)$. Nevertheless, we could observe a moderate heterogeneity in severe OSAS group $\left(\mathrm{I}^{2}=62.9 \%\right.$, $\mathrm{P}=0.068$ ) (Figure $4 B$ ).

\section{Other subgroups}

When we took the comorbidities of CVD into consideration, we divided the OSAS patients into two subgroups: OSAS subjects without CVD or with/without CVD, according to the inclusion criteria of each eligible study (details in the Table 1). Hematological parameters (WBC, MPV and PDW) still revealed a developed trend in OSAS subjects without CVD and indices (LYM, NLR, MPV, PDW) in OSAS subjects with/without CVD. It was noteworthy that the overall pooled analyses of neutrophil and PLR subgroups showed no significant increase or decrease just because they exhibited an opposite trend in OSAS subjects without CVD or with/without CVD. Subgroup of RDW and HCT only available in OSAS subjects with/without CVD (details in Table S4).

\section{Sensitivity analysis}

Although all the subgroups showed a moderate or significant heterogeneity, the sensitivity analyses couldn't found out the source of heterogeneity excepted the PLR subgroup.

\section{Publication bias}

We summarized the $\mathrm{P}$ values of Egger's test and Begg's test of each subgroup into a publication bias table (Table S5). And all the results suggested that there were no evidence of publication bias $(\mathrm{P}>0.05)$.

\section{Discussion}

OSAS is characterized by recurrent obstruction of partial or total upper airway during sleep, causing more than ten seconds of breathing (apnea) cessation, despite ongoing respiratory effort. Our results showed that there was a positive correlation between the levels of hematological indices and the severity of OSAS including WBC, LYM, NLR, MPV, PDW, PLR, RDW and HCT. That meant the higher the AHI, the higher the levels. To the best of our knowledge, this is the first meta-analysis to analyze the association between hematological parameters and the
OSAS severity.

\section{Clinical implication}

We proposed the hematological indices (WBC, LYM, NLR, MPV, PDW, PLR, RDW and HCT) could be alternative markers to evaluate the inflammation in OSAS patients, which was useful to assess the severity of OSAS. Moreover, the elevated hematological parameters could assist in timely identification of high-risk OSAS patients and alert clinicians to the potential increased risk of CVDs in them. As compare with the present biochemical markers used clinically, such as IL6 and C-reactive protein, hematological parameters were comparatively cheap, readily-measurable, easy and practical laboratory markers, especially in developing countries. Besides, blood routine examination is used more frequently than disease-specific biochemical markers in primary hospital.

\section{Possible mechanisms}

OSAS is a chronic disease which can lead to various comorbidities in subject with the degree of OSAS severity, including pulmonary disease, endocrine dysfunction, and cognitive impairment (42-44). And CVD occupies a large part among the comorbidities (4-6). Newman et al. (45), Lattanzi et al. $(46,47)$ and Javaheri et al. (48) found that patients with OSAS had an increased risk of CVDs and suggested that OSAS was a major risk factor for CVDs. For example, the autonomic and neurohumoral abnormalities perpetuated beyond the offending obstructive events and persisted into the daytime, resulting in a disturbance of the overall circadian blood pressure rhythm and an increase in short- and long-term blood pressure variability $(46,47,49)$. The high absolute blood pressure levels but even their fluctuations were related to development and progression of organ damage by promoting arterial remodelling, microvascular damage, hemodynamic instability, and vascular reactivity impairment (50-53).

The relationship between OSAS and accompanying changes of hematological parameters is complicated. Three main mechanisms may be implicated as follow.

First, acute and chronic hypoxia may be associated with the changes of MPV, PDW, HCT. Nena et al. (19) found that MPV and PDW were negative related to average $\mathrm{SpO}_{2}$ and minimum $\mathrm{SpO}_{2}$ and implied that hypoxia could activate platelet function. And Rahangdale et al. (54) demonstrated that high level of oxygen desaturation was 
linked with higher platelet surface adhesion molecules, activated glycoprotein receptor expression, plateletmonocyte aggregation and platelet-neutrophil aggregation. Moreover, a fundamental research demonstrated chronic intermittent hypoxia increases platelet reactivity directly in rats (55). As to the parameters of red blood cell, Hematocrit is more closely tied to hypoxia. It is well known that hypoxemic state is interrelated with high hematocrit levels, as oxyhemoglobin desaturation can stimulate erythropoiesis, leading to increased hematocrit. Svatikova et al. (56) reported that ANP (atrial natriuretic peptide) was increased overnight in those untreated OSAS patients, and ANP levels decreased with CPAP treatment. It indicated that hemoconcentration might lead to increased hematocrit.

Second mechanism appears to be sympathetic overactivity. It results in many pathophysiological changes such as episodic hypoxemia, recurrent arousals and increased inspiratory effort. OSAS patients exhibited high levels of sympathetic nerve activity even when they were fully awake, which contributed to platelet activation and CVDs (57). Larsson et al. (58) suggested that platelet aggregability was increased by high levels of circulating catecholamine in vivo. Therefore, hematological indices associated with platelet activation (MPV, PDW, PLR) might change in OSAS patients caused by catecholamine discharge. On the other hand, the continuous high level of catecholamine contributes to hypertension, endothelial dysfunction and organ damage. And CVDs have a close relation with hematological parameters. For example, RDW has been found to be negative associated with the outcomes of heart failure, pulmonary hypertension and many other CVDs. Also, previous studies showed that there was a significant correlation between the RDW values and the AHI $(23,35)$.

The third mechanism is chronic inflammation. The importance of inflammatory processes in the pathogenesis of OSAS has been strongly supported by a great number of studies (12). Moreover, Yokoe et al. (59) demonstrated that elevated inflammatory markers in OSAS patients significantly decreased after CPAP treatment (17). Some fundamental researches declared that Nuclear

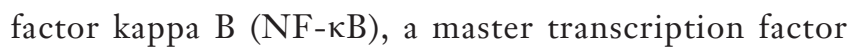
regulated the downstream inflammatory gene expression, was found to be selective activated by hypoxia and reoxygenation (60). NF- $\mathrm{kB}$ activity also resulted in an increased number of circulating neutrophils and monocytes. And the apoptosis of neutrophils was dysregulated in the process of OSAS (61). Both lead to the elevated level of neutrophil in peripheral blood of OSAS patients. As for lymphocyte, OSAS patients combined with CVDs were found to have a lower lymphocyte levels compared to those without CVDs, which could be due to the uncontrolled inflammatory pathway (62). Moreover, some researchers demonstrated that lower lymphocyte counts were related to activation of the hypothalamus-hypophysis-adrenal (THA) axis, increase production of systemic cortisol levels and altered sleeping habits (63). The NLR, a novel marker of systemic inflammation, was associated with many chronic diseases, also could be an indicator used to predict CVDs in OSAS patients (32). On the other hand, many proinflammatory cytokines, such as IL6, could significantly promote the production and activation of platelet, which contributed to the changes of those hematological parameters including PLR, MPV and PDW (64).

In summary, derangements including acute/chronic hypoxia, sympathetic overactivity, chronic systematic inflammation and even neurohumoral abnormalities interacted with each other synergistically rather than independently in the development of severity and complication of OSAS.

\section{Limitation}

Several limitations of our meta-analysis might be outlined as follows. First, all the eligible studies were retrospective studies and used observational data, which made it difficult to identify the causal relationship between hematological parameters and OSAS severity for possible residual confounding from unmeasured variables might exist. Second, although all the blood samples from different patients during data-gathering process were detected timely, it couldn't be guaranteed that the process was performed with identical methods at different times. And some minute differences still existed in several studies. For example, Sökücü et al. (35) used automatic analyzers instead of manual microscopic counting used by Nena et al. (19). Third, all hematological indices were performed with just one single measurement. Therefore, it was unsure whether the positive correlation was continuous or temporal. Fourth, although some hematological indices were considered as inflammatory markers, such as NLR and PLR, it was supposed to use classical established inflammatory markers like IL6 as a reference for comparison during detection process $(12,13,21)$. Fifth, the 
exclusion criteria in the subgroup of OSAS subjects without CVD was mainly dependent on the past medical history and physical examination, which making possible coexistence of asymptomatic cardiovascular diseases. And only some studies excluded the influence of recent medication history of antiplatelet drugs (such as aspirin) when detecting MPV, PDW and PLR. Sixth, all eligible studies were preliminary researches without further fundamental mechanism research. And the cut-off point of hematological indices values determining an individual's OSAS severity risk was unclear which needed further detailed study. Seventh, another two studies (ineligible studies) already declared the HCT and NLR were decreased after CPAP therapy in OSAS patients $(65,66)$. But since the small sample size, further prospective study with adequate large sample size was desirable. At last, Heterogeneity in our meta-analysis was comparatively significant. But the sensitivity analyses couldn't found out the source of heterogeneity except the PLR subgroup. And although we changed median $(\mathrm{Q} 25-\mathrm{Q} 75)$ into mean $\pm \mathrm{SD}$ following the Cochrane handbook, it still might cause bias.

\section{Suggestions for future}

However, because all eligible studies were preliminary researches, the result of our meta-analysis was considered as a proposal. Further prospective studies are warranted to implement the finding to evaluate the prognostic outcomes of OSAS patients with elevated hematological indices, the practical utility in improving cardiovascular outcomes and monitoring the effects of continuous positive airway pressure (CPAP) therapy.

Therefore, we make four suggestions for further research. First, more research data in this field from different countries are needed for the present studies are mainly from Turkey. Second, it is supposed to use classical established inflammatory markers like IL6 as a reference for comparison during detection process. Third, the cutoff point of hematological indices values determining an individual's OSAS severity risk need further detailed study. Researchers may use receiver operating characteristic (ROC) curve analysis to determine the cut-off value of hematological indices when used to predict the severity or complication of OSAS, because ROC analysis could provide sensitivity, specificity, positive predictive value, negative predictive value, and diagnostic accuracy for all tests respectively. Fourth, further prospective studies with adequate large sample size are warrant, which might focus on the change of hematological parameters in OSAS patients before and after medical or surgical treatment.

\section{Conclusions}

Hematological indices are comparatively simple, inexpensive and practical severity markers of obstructive sleep apnea syndrome including WBC, LYM, NLR, MPV, PDW, PLR, RDW and HCT. But further prospective studies are warranted to substantiate our findings.

\section{Acknowledgements}

None.

\section{Footnote}

Conflicts of Interest: The authors have no conflicts of interest to declare.

\section{References}

1. Peppard PE, Young T, Barnet JH, et al. Increased prevalence of sleep-disordered breathing in adults. Am J Epidemiol 2013;177:1006-14.

2. American Academy of Sleep Medicine. International Classification of Sleep Disorders. 3rd ed. IL: American Academy of Sleep Medicine, 2014.

3. Dewan NA, Nieto FJ, Somers VK. Intermittent hypoxemia and OSA: implications for comorbidities. Chest 2015;147:266-74.

4. Marin JM, Carrizo SJ, Vicente E, et al. Long-term cardiovascular outcomes in men with obstructive sleep apnoea-hypopnoea with or without treatment with continuous positive airway pressure: an observational study. Lancet 2005;365:1046-53.

5. Peker Y, Hedner J, Norum J, et al. Increased incidence of cardiovascular disease in middle-aged men with obstructive sleep apnea: a 7-year follow-up. Am J Respir Crit Care Med 2002;166:159-65.

6. Dempsey JA, Veasey SC, Morgan BJ, et al. Pathophysiology of sleep apnea. Physiol Rev 2010;90:47-112.

7. El Solh AA, Akinnusi ME, Baddoura FH, et al. Endothelial cell apoptosis in obstructive sleep apnea: a link to endothelial dysfunction. Am J Respir Crit Care Med 2007;175:1186-91.

8. Badran M, Ayas N, Laher I. Cardiovascular complications 
of sleep apnea: role of oxidative stress. Oxid Med Cell Longev 2014;2014:985258.

9. Jelic S, Padeletti M, Kawut SM, et al. Inflammation, oxidative stress, and repair capacity of the vascular endothelium in obstructive sleep apnea. Circulation 2008;117:2270-8.

10. Garvey JF, Taylor CT, McNicholas WT. Cardiovascular disease in obstructive sleep apnoea syndrome: the role of intermittent hypoxia and inflammation. Eur Respir J 2009;33:1195-205.

11. Tamisier R, Pepin JL, Remy J, et al 14 nights of intermittent hypoxia elevate daytime blood pressure and sympathetic activity in healthy humans. Eur Respir J 2011;37:119-28.

12. Nadeem R, Molnar J, Madbouly EM, et al. Serum inflammatory markers in obstructive sleep apnea: a metaanalysis. J Clin Sleep Med 2013;9:1003-12.

13. Turak O, Ozcan F, Isleyen A, et al. Usefulness of neutrophil-to-lymphocyte ratio to predict in-hospital outcomes in infective endocarditis. Can J Cardiol 2013;29:1672-8.

14. Lattanzi S, Cagnetti C, Provinciali L, et al. Neutrophil-tolymphocyte ratio and neurological deterioration following acute cerebral hemorrhage. Oncotarget 2017;8:57489-94.

15. Lattanzi S, Cagnetti C, Rinaldi C, et al. Neutrophil-tolymphocyte ratio improves outcome prediction of acute intracerebral hemorrhage. J Neurol Sci 2018;387:98-102.

16. Lattanzi S, Cagnetti C, Provinciali L, et al. Neutrophilto-Lymphocyte Ratio Predicts the Outcome of Acute Intracerebral Hemorrhage. Stroke 2016;47:1654-7.

17. Yu S, Arima H, Bertmar C, et al. Neutrophil to lymphocyte ratio and early clinical outcomes in patients with acute ischemic stroke. J Neurol Sci 2018;387:115-8.

18. de Jager CP, van Wijk PT, Mathoera RB, et al. Lymphocytopenia and neutrophil-lymphocyte count ratio predict bacteremia better than conventional infection markers in an emergency care unit. Crit Care 2010;14:R192.

19. Nena E, Papanas N, Steiropoulos P, et al. Mean Platelet Volume and Platelet Distribution Width in non-diabetic subjects with obstructive sleep apnoea syndrome: new indices of severity? Platelets 2012;23:447-54.

20. Varol E, Ozturk O, Gonca T, et al. Mean platelet volume is increased in patients with severe obstructive sleep apnea. Scand J Clin Lab Invest 2010;70:497-502.

21. Dotsenko O, Chaturvedi N, Thom SA, et al. Platelet and leukocyte activation, atherosclerosis and inflammation in European and South Asian men. J Thromb Haemost
2007;5:2036-42.

22. Choi JB, Loredo JS, Norman D, et al. Does obstructive sleep apnea increase hematocrit? Sleep Breath 2006;10:155-60.

23. Ozsu S, Abul Y, Gulsoy A, et al. Red cell distribution width in patients with obstructive sleep apnea syndrome. Lung 2012;190:319-26.

24. Moher D, Liberati A, Tetzlaff J, et al. Preferred reporting items for systematic reviews and meta-analyses: the PRISMA statement. PLoS Med 2009;6:e1000097.

25. Berry RB, Budhiraja R, Gottlieb DJ, et al. Rules for scoring respiratory events in sleep: update of the 2007 AASM Manual for the Scoring of Sleep and Associated Events. Deliberations of the Sleep Apnea Definitions Task Force of the American Academy of Sleep Medicine. J Clin Sleep Med 2012;8:597-619.

26. Effective Public Health Practice Project Quality Assessment Tool (Hamilton, Ontario, Canada). Available online: http://www.ephpp.ca/tools.html

27. Cochrane Handbook for Systematic Reviews of Interventions. Available online: http://handbook. cochrane.org/chapter_7/7_7_3_5_mediansand_ interquartile_ranges.htm

28. Koseoglu S, Ozcan KM, Ikinciogullari A, et al. Relationship Between Neutrophil to Lymphocyte Ratio, Platelet to Lymphocyte Ratio and Obstructive Sleep Apnea Syndrome. Adv Clin Exp Med 2015;24:623-7.

29. Sunnetcioglu A, Gunbatar H, Yildiz H. Red cell distribution width and uric acid in patients with obstructive sleep apnea. Clin Respir J 2018;12:1046-52.

30. Song YJ, Kwon JH, Kim JY, et al. The platelet-tolymphocyte ratio reflects the severity of obstructive sleep apnea syndrome and concurrent hypertension. Clin Hypertens 2016;22:1.

31. Koseoglu HI, Altunkas F, Kanbay A, et al. Plateletlymphocyte ratio is an independent predictor for cardiovascular disease in obstructive sleep apnea syndrome. J Thromb Thrombolysis 2015;39:179-85.

32. Uygur F, Tanriverdi H, Aktop Z, et al. The neutrophil-tolymphocyte ratio in patients with obstructive sleep apnoea syndrome and its relationship with cardiovascular disease. Heart Lung 2016;45:121-5.

33. Altintas N, Cetinoglu E, Yuceege M, et al. Neutrophilto-lymphocyte ratio in obstructive sleep apnea; a multi center, retrospective study. Eur Rev Med Pharmacol Sci 2015;19:3234-40.

34. Kanbay A, Tutar N, Kaya E, et al. Mean platelet volume in patients with obstructive sleep apnea syndrome and its 
relationship with cardiovascular diseases. Blood Coagul Fibrinolysis 2013;24:532-6.

35. Sökücü SN, Ozdemir C, Dalar L, et al. Is mean platelet volume really a severity marker for obstructive sleep apnea syndrome without comorbidities? Pulm Med 2014;2014:754839.

36. Yenigun A, Karamanli H. Investigation of the relationship between neutrophil-to-lymphocyte ratio and obstructive sleep apnoea syndrome. J Laryngol Otol 2015;129:887-92.

37. Korkmaz M, Korkmaz H, Kucuker F, et al. Evaluation of the association of sleep apnea-related systemic inflammation with CRP, ESR, and neutrophil-tolymphocyte ratio. Med Sci Monit 2015;21:477-81.

38. Varol E, Ozturk O, Yucel H, et al. The effects of continuous positive airway pressure therapy on mean platelet volume in patients with obstructive sleep apnea. Platelets 2011;22:552-6.

39. Karaka MS, Altekin RE, Baktir AO, et al. Association between mean platelet volume and severity of disease in patients with obstructive sleep apnea syndrome without risk factors for cardiovascular disease. Turk Kardiyol Dern Ars 2013;41:14-20.

40. Kurt OK, Yildiz N. The importance of laboratory parameters in patients with obstructive sleep apnea syndrome. Blood Coagul Fibrinolysis 2013;24:371-4.

41. Sökücü SN, Karasulu L, Dalar L, et al. Can red blood cell distribution width predict severity of obstructive sleep apnea syndrome? J Clin Sleep Med 2012;8:521-5.

42. Banks S, Dinges DF. Behavioral and physiological consequences of sleep restriction. J Clin Sleep Med 2007;3:519-28.

43. Meerlo P, Sgoifo A, Suchecki D. Restricted and disrupted sleep: effects on autonomic function, neuroendocrine stress systems and stress responsivity. Sleep Med Rev 2008;12:197-210.

44. Mirrakhimov AE. Obstructive sleep apnea and kidney disease: is there any direct link? Sleep Breath 2012;16:1009-16.

45. Newman AB, Nieto FJ, Guidry U, et al. Relation of sleep-disordered breathing to cardiovascular disease risk factors: the Sleep Heart Health Study. Am J Epidemiol 2001;154:50-9.

46. Lattanzi S, Brigo F, Silvestrini M. Blood pressure profile and nocturnal oxygen desaturation. J Clin Hypertens (Greenwich) 2018;20:656-8.

47. Lattanzi S, Brigo F, Silvestrini M. Obstructive sleep apnea syndrome and the nocturnal blood pressure profile. J Clin
Hypertens (Greenwich) 2018;20:1036-8.

48. Javaheri S, Parker TJ, Liming JD, et al. Sleep apnea in 81 ambulatory male patients with stable heart failure. Types and their prevalences, consequences, and presentations. Circulation 1998;97:2154-9.

49. Lattanzi S, Vernieri F, Silvestrini M. Blood pressure variability and neurocognitive functioning. J Clin Hypertens (Greenwich) 2018;20:645-7.

50. Wang J, Shi X, Ma C, et al. Visit-to-visit blood pressure variability is a risk factor for all-cause mortality and cardiovascular disease: a systematic review and metaanalysis. J Hypertens 2017;35:10-7.

51. Tedla YG, Yano Y, Carnethon M, et al. Association Between Long-Term Blood Pressure Variability and 10Year Progression in Arterial Stiffness: The Multiethnic Study of Atherosclerosis. Hypertension 2017;69:118-27.

52. Lattanzi S, Carbonari L, Pagliariccio G, et al. Neurocognitive functioning and cerebrovascular reactivity after carotid endarterectomy. Neurology 2018;90:e307-e315.

53. Ribeiro AH, Lotufo PA, Fujita A, et al. Association Between Short-Term Systolic Blood Pressure Variability and Carotid Intima-Media Thickness in ELSA-Brasil Baseline. Am J Hypertens 2017;30:954-60.

54. Rahangdale S, Yeh SY, Novack V, et al. The influence of intermittent hypoxemia on platelet activation in obese patients with obstructive sleep apnea. J Clin Sleep Med 2011;7:172-8.

55. Dunleavy M, Dooley M, Cox D, et al. Chronic intermittent asphyxia increases platelet reactivity in rats. Exp Physiol 2005;90:411-6.

56. Svatikova A, Shamsuzzaman AS, Wolk R, et al. Plasma brain natriuretic peptide in obstructive sleep apnea. Am J Cardiol 2004;94:529-32.

57. Abboud F, Kumar R. Obstructive sleep apnea and insight into mechanisms of sympathetic overactivity. J Clin Invest 2014;124:1454-7.

58. Larsson PT, Hjemdahl P, Olsson G, et al. Altered platelet function during mental stress and adrenaline infusion in humans: evidence for an increased aggregability in vivo as measured by filtragometry. Clin Sci (Lond) 1989;76:369-76.

59. Yokoe T, Minoguchi K, Matsuo H, et al. Elevated levels of C-reactive protein and interleukin-6 in patients with obstructive sleep apnea syndrome are decreased by nasal continuous positive airway pressure. Circulation 2003;107:1129-34.

60. Ryan S, Taylor CT, McNicholas WT. Selective activation 
of inflammatory pathways by intermittent hypoxia in obstructive sleep apnea syndrome. Circulation 2005;112:2660-7.

61. Dyugovskaya L, Polyakov A, Lavie P, et al. Delayed neutrophil apoptosis in patients with sleep apnea. Am J Respir Crit Care Med 2008;177:544-54.

62. Altunayoglu Cakmak V, Ozsu S, Gulsoy A, et al. The Significance of the Relative Lymphocyte Count as an Independent Predictor of Cardiovascular Disease in Patients with Obstructive Sleep Apnea Syndrome. Med Princ Pract 2016;25:455-60.

63. Acanfora D, Gheorghiade M, Trojano L, et al. Relative lymphocyte count: a prognostic indicator of mortality in elderly patients with congestive heart failure. Am Heart J 2001;142:167-73.

64. Norol F, Vitrat N, Cramer E, et al. Effects of cytokines on platelet production from blood and marrow CD34+ cells. Blood 1998;91:830-43.

65. Oyama J, Nagatomo D, Yoshioka G, et al. The relationship between neutrophil to lymphocyte ratio, endothelial function, and severity in patients with obstructive sleep apnea. J Cardiol 2016;67:295-302.

66. Feliciano A, Linhas R, Marçôa R, et al. Hematological evaluation in males with obstructive sleep apnea before and after positive airway pressure. Rev Port Pneumol (2006) 2017;23:71-8.

Cite this article as: $\mathrm{Wu} \mathrm{M,} \mathrm{Zhou} \mathrm{L,} \mathrm{Zhu} \mathrm{D,} \mathrm{Lai} \mathrm{T,} \mathrm{Chen} \mathrm{Z,}$ Shen H. Hematological indices as simple, inexpensive and practical severity markers of obstructive sleep apnea syndrome: a meta-analysis. J Thorac Dis 2018;10(12):6509-6521. doi: $10.21037 /$ jtd.2018.10.105 
Table S1 Demographic data of eligible studies

\begin{tabular}{|c|c|c|c|c|c|c|c|c|}
\hline Author & Year & Total size & Group* & $\mathrm{AHI}$ & Size & Age & BMI $\left(\mathrm{kg} / \mathrm{m}^{2}\right)$ & Male (\%) \\
\hline \multirow[t]{4}{*}{ Sunnetcioglu } & 2018 & 600 & Control & $2.6 \pm 1.4$ & 197 & $40 \pm 11.5$ & $28.3 \pm 4.7$ & $152(77.1)$ \\
\hline & & & Mild OSAS & $9.2 \pm 3.1$ & 149 & $44.5 \pm 11.3$ & $30.1 \pm 5.2$ & $113(75.8)$ \\
\hline & & & Moderate OSAS & $21.5 \pm 4$ & 98 & $48.7 \pm 10.5$ & $32 \pm 6.8$ & $69(70.4)$ \\
\hline & & & Severe OSAS & $57.6 \pm 24.1$ & 156 & $48.5 \pm 12$ & $33 \pm 7.1$ & $122(78.2)$ \\
\hline \multirow[t]{4}{*}{ Song } & 2016 & 290 & Control & NA & 61 & $44 \pm 15.4$ & $24.2 \pm 4.43$ & $33(54.1)$ \\
\hline & & & Mild OSAS & NA & 67 & $48.2 \pm 13.4$ & $24.7 \pm 3.2$ & $39(58.2)$ \\
\hline & & & Moderate OSAS & NA & 61 & $49.1 \pm 11.8$ & $26.4 \pm 3.58$ & $41(67.2)$ \\
\hline & & & Severe OSAS & NA & 101 & $51.4 \pm 12.5$ & $26.9 \pm 3.41$ & $80(79.2)$ \\
\hline \multirow[t]{4}{*}{ Uygur } & 2016 & 289 & Control & $2.2 \pm 1.3$ & 118 & $50.3 \pm 11.7$ & $29.4 \pm 7.8$ & $61(57.0)$ \\
\hline & & & Mild OSAS & $11.3 \pm 2.2$ & 57 & $53.7 \pm 10.8$ & $30.8 \pm 5.7$ & $36(21.0)$ \\
\hline & & & Moderate OSAS & $23.7 \pm 3.6$ & 53 & $51.8 \pm 12.1$ & $31.6 \pm 8.1$ & $30(23.0)$ \\
\hline & & & Severe OSAS & $56.1 \pm 18.7$ & 61 & $54.5 \pm 12.7$ & $32.1 \pm 7.1$ & $39(22.0)$ \\
\hline \multirow[t]{4}{*}{ Altintas } & 2015 & 561 & Control & NA & 80 & $47.3 \pm 10.8$ & $32.5 \pm 7.8$ & $56(70.0)$ \\
\hline & & & Mild OSAS & $9.83 \pm 2.66$ & 163 & $48.9 \pm 12.8$ & $32.4 \pm 7.3$ & $90(73.0)$ \\
\hline & & & Moderate OSAS & $21.44 \pm 4.46$ & 158 & $48.3 \pm 10.8$ & $32.6 \pm 8.4$ & $111(70.0)$ \\
\hline & & & Severe OSAS & $62.8 \pm 25.01$ & 160 & $48.9 \pm 10.5$ & $34.3 \pm 7.5$ & $110(69.0)$ \\
\hline \multirow[t]{4}{*}{ Korkmaz } & 2015 & 146 & Control & NA & 40 & $43.4 \pm 11.14$ & 29.27 & $14(35.0)$ \\
\hline & & & Mild OSAS & NA & 27 & $44.96 \pm 9.25$ & 29.15 & $18(67.0)$ \\
\hline & & & Moderate OSAS & NA & 37 & $47.24 \pm 9.12$ & 31.97 & $21(57.0)$ \\
\hline & & & Severe OSAS & NA & 42 & $49.35 \pm 9.79$ & 32.6 & $26(62.0)$ \\
\hline \multirow[t]{4}{*}{ Koseoglu } & 2015 & 424 & Control & $2.6 \pm 2.1$ & 57 & $43.5 \pm 11.2$ & $29 \pm 4.8$ & $23(40.0)$ \\
\hline & & & Mild OSAS & $10.6 \pm 7.2$ & 93 & $51.1 \pm 8.6$ & $30.2 \pm 4.8$ & $58(62.0)$ \\
\hline & & & Moderate OSAS & $21.8 \pm 3.8$ & 82 & $51.1 \pm 10.9$ & $32.4 \pm 6.4$ & $62(76.0)$ \\
\hline & & & Severe OSAS & $58.5 \pm 24.1$ & 192 & $51.6 \pm 10.6$ & $35.3 \pm 7.2$ & $139(72.0)$ \\
\hline \multirow[t]{4}{*}{ Koseoglu } & 2015 & 284 & Control & NA & 48 & $43.08 \pm 8.88$ & $27.0 \pm 3.76$ & $29(60.4)$ \\
\hline & & & Mild OSAS & NA & 67 & $47.2 \pm 10.14$ & $30.67 \pm 4.6$ & $167(70.7)$ \\
\hline & & & Moderate OSAS & NA & 61 & & & \\
\hline & & & Severe OSAS & NA & 108 & & & \\
\hline \multirow[t]{4}{*}{ Yenigun } & 2015 & 136 & Control & NA & 38 & $48.08 \pm 8.82$ & $30.5 \pm 6.16$ & $20(52.0)$ \\
\hline & & & Mild OSAS & NA & 34 & $46.75 \pm 8.06$ & $33.9 \pm 6.79$ & $24(70.0)$ \\
\hline & & & Moderate OSAS & NA & 30 & $53.64 \pm 12.6$ & $33.5 \pm 6.66$ & $14(46.0)$ \\
\hline & & & Severe OSAS & NA & 34 & $52.9 \pm 12.21$ & $36.1 \pm 6.63$ & $18(53.0)$ \\
\hline \multirow[t]{4}{*}{ Sokucu } & 2014 & 200 & Control & $2.84 \pm 1.41$ & 30 & $38.4 \pm 12.29$ & $26.9 \pm 4.61$ & $15(50.0)$ \\
\hline & & & Mild OSAS & $9.58 \pm 2.91$ & 38 & $43.5 \pm 12.15$ & $29.1 \pm 4.51$ & $30(78.9)$ \\
\hline & & & Moderate OSAS & $21.12 \pm 3.88$ & 41 & $47.2 \pm 10.95$ & $30.0 \pm 4.52$ & $33(80.5)$ \\
\hline & & & Severe OSAS & $54.1 \pm 18.81$ & 91 & $45.6 \pm 10.15$ & $31.7 \pm 4.53$ & $76(83.5)$ \\
\hline \multirow[t]{4}{*}{ Kanbay } & 2013 & 205 & Control & NA & 35 & $51.2 \pm 12.6$ & $29.2 \pm 8.4$ & $22(63.0)$ \\
\hline & & & Mild OSAS & NA & 20 & $55.6 \pm 11.6$ & $31.4 \pm 5.2$ & $13(65.0)$ \\
\hline & & & Moderate OSAS & NA & 42 & $52.9 \pm 13.3$ & $31.7 \pm 7.5$ & $20(47.0)$ \\
\hline & & & Severe OSAS & NA & 108 & $55.5 \pm 11.9$ & $32.4 \pm 6.1$ & $74(68.0)$ \\
\hline \multirow[t]{4}{*}{ Karakas } & 2013 & 124 & Control & NA & 31 & $46.7 \pm 8.4$ & $28.9 \pm 2.9$ & NA \\
\hline & & & Mild OSAS & $10.3 \pm 3$ & 30 & $46.1 \pm 8.2$ & $28.4 \pm 3.1$ & NA \\
\hline & & & Moderate OSAS & $21.5 \pm 3.5$ & 32 & $48.3 \pm 7.6$ & $28.7 \pm 2.7$ & NA \\
\hline & & & Severe OSAS & $59.4 \pm 15.9$ & 31 & $47.3 \pm 7.7$ & $29.2 \pm 2.9$ & NA \\
\hline \multirow[t]{4}{*}{ Kurt } & 2013 & 98 & Control & NA & 20 & $46.3 \pm 13.1$ & $29.4 \pm 4.9$ & $11(55.0)$ \\
\hline & & & Mild OSAS & NA & 15 & $51.7 \pm 8.9$ & $28.4 \pm 3.3$ & $11(73.0)$ \\
\hline & & & Moderate OSAS & NA & 26 & $53.9 \pm 12.4$ & $31.7 \pm 4.8$ & $15(58.0)$ \\
\hline & & & Severe OSAS & NA & 37 & $58.1 \pm 10.9$ & $33.2 \pm 5.7$ & $25(68.0)$ \\
\hline Nena & 2012 & 610 & Control & NA & 148 & $53.4 \pm 12.5$ & $35 \pm 7.2$ & NA \\
\hline & & & Mild OSAS & & 121 & & & \\
\hline & & & Moderate OSAS & & 85 & & & \\
\hline & & & Severe OSAS & & 256 & & & \\
\hline Ozsu & 2012 & 137 & Control & $2.5 \pm 1.4$ & 25 & 50 [23-67] & 30 [25-41] & $7(28.0)$ \\
\hline & & & Mild OSAS & $10.5 \pm 3.4$ & 15 & 51 [21-77] & 32.4 [24-69] & $9(60.0)$ \\
\hline & & & Moderate OSAS & $21.7 \pm 3.7$ & 26 & 49 [21-76] & 27 [22-52] & $18(69.0)$ \\
\hline & & & Severe OSAS & $60.2 \pm 22$ & 71 & 53 [30-73] & 32 [21-62] & $51(72.0)$ \\
\hline Varol & 2011 & 56 & Control & $2.8 \pm 1.6$ & 25 & $49.6 \pm 8.5$ & $30.9 \pm 2.9$ & $14(56.0)$ \\
\hline & & & Severe OSAS & $55.8 \pm 15.1$ & 31 & $53.8 \pm 9.2$ & $32.5 \pm 3.3$ & $21(67.0)$ \\
\hline Varol & 2010 & 95 & Control & $2.6 \pm 1.4$ & 24 & $45.6 \pm 13.9$ & $28.2 \pm 5$ & $14(58.0)$ \\
\hline & & & $\begin{array}{l}\text { Mild-moderate } \\
\text { OSAS }\end{array}$ & $15.6 \pm 7.5$ & 42 & $50.1 \pm 9.3$ & $29 \pm 4.1$ & $22(52.0)$ \\
\hline & & & Severe OSAS & $56.5 \pm 22.4$ & 29 & $49.6 \pm 10.2$ & $31.5 \pm 4$ & $21(72.0)$ \\
\hline Choi & 2006 & 263 & Control & $2.8 \pm 1.3$ & 61 & $37.6 \pm 8.4$ & $24.9 \pm 3.8$ & $29(37.7)$ \\
\hline & & & $\begin{array}{l}\text { Mild-moderate } \\
\text { OSAS }\end{array}$ & $15.7 \pm 7.3$ & 91 & $44.1 \pm 8.9$ & $28.5 \pm 5$ & $62(68.1)$ \\
\hline & & & Severe OSAS & $67.2 \pm 25.8$ & 111 & $47.3 \pm 9.3$ & $32 \pm 5.5$ & $98(88.3)$ \\
\hline
\end{tabular}

Total was based on means and standard deviations, except that Ozsu was based on medians and ranges. *, according to the AHI, all eligible studies subjects were categorized into four groups: control subjects ( $\mathrm{AHI}<5$ events/hour), mild subjects ( 5 events/hour $\leq \mathrm{AHI} \leq 15$ events/hour, moderate subjects (15 events/hour $\leq \mathrm{AHI} \leq 30$ events/hour) and severe subjects (AHI e30 events/hour). AHI, apnea-hypopnea index; BMI, body mass index. 
Table S2 Quality assessment of included studies using the EPHPP tool*

\begin{tabular}{|c|c|c|c|c|c|}
\hline Author/year & $\begin{array}{l}\text { Overall quality } \\
\text { assessment }\end{array}$ & \multicolumn{4}{|c|}{ Quality assessment for study components } \\
\hline Song 2016 & Strong & Strong & Moderate & Strong & Moderate \\
\hline Korkmaz 2015 & Strong & Strong & Moderate & Strong & Strong \\
\hline Koseoglu 2015 & Strong & Strong & Moderate & Strong & Moderate \\
\hline Koseoglu 2015 & Strong & Strong & Moderate & Strong & Strong \\
\hline Karakas 2013 & Strong & Strong & Moderate & Strong & Strong \\
\hline Kurt 2013 & Strong & Strong & Moderate & Strong & Moderate \\
\hline Nena 2012 & Strong & Strong & Moderate & Strong & Strong \\
\hline Ozsu 2012 & Strong & Strong & Moderate & Strong & Moderate \\
\hline Varol2011 & Strong & Strong & Moderate & Strong & Moderate \\
\hline Varol2010 & Strong & Strong & Moderate & Strong & Moderate \\
\hline Choi 2006 & Strong & Strong & Moderate & Strong & Strong \\
\hline
\end{tabular}

*, EPHPP: Effective Public Health Practice Project tool (Hamilton, Ontario, Canada); ${ }^{1}$, original data was based on median (Q25-Q75), and we changed it into mean $\pm \mathrm{SD}$, according to the Cochrane handbook. 
Table S3 Detailed primary data of each hematological parameters

\begin{tabular}{|c|c|c|c|c|c|c|c|c|c|c|c|c|c|}
\hline \multirow{2}{*}{ Group } & \multirow{2}{*}{ Author/year } & \multicolumn{3}{|c|}{ Control group } & \multicolumn{3}{|c|}{ Mild OSAS group } & \multicolumn{3}{|c|}{ Moderate OSAS group } & \multicolumn{3}{|c|}{ Severe OSAS group } \\
\hline & & $\mathrm{N}$ & Mean & SD & $\mathrm{N}$ & Mean & SD & $\mathrm{N}$ & Mean & SD & $\mathrm{N}$ & Mean & SD \\
\hline \multirow[t]{12}{*}{ WBC $\left(10^{9} / \mathrm{L}\right)$} & Altintas 2015 & 80 & 3.34 & 0.45 & 163 & 3.37 & 0.49 & 158 & 3.32 & 0.526 & 160 & 4.29 & 0.319 \\
\hline & Uygur 2016 & 118 & 6.1 & 1.3 & 57 & 6.7 & 1.2 & 53 & 7.2 & 1.4 & 61 & 7.8 & 1.5 \\
\hline & Kanbay 2013 & 35 & 8.6 & 1.8 & 20 & 9.2 & 1.4 & 42 & 7.8 & 1.6 & 108 & 8.8 & 2.3 \\
\hline & Korkmaz 2015 & 40 & 6.999 & 1.566 & 27 & 7.751 & 2.27 & 37 & 7.039 & 1.55 & 42 & 7.194 & 1.491 \\
\hline & Kurt 2013 & 20 & 7.636 & 1.872 & 15 & 7.375 & 1.66 & 26 & 7.04 & 1.355 & 37 & 7.506 & 1.656 \\
\hline & Sökücü 2014 & 30 & 7.08 & 1.37 & 38 & 7.27 & 1.97 & 41 & 7.83 & 1.79 & 91 & 7.89 & 1.99 \\
\hline & Yenigun 2015 & 38 & 6.61 & 1.13 & 34 & 8.32 & 1.76 & 30 & 8.2 & 1.87 & 34 & 9.34 & 1.33 \\
\hline & Song 2016 & 61 & 6.759 & 1.806 & 67 & 7.283 & 2.031 & 61 & 7.314 & 2.976 & 101 & 7.724 & 2.051 \\
\hline & Choi 2006 & 61 & 5.7 & 1.8 & - & - & - & - & - & - & 111 & 6.6 & 1.9 \\
\hline & Varol 2010 & 24 & 8.6 & 2.2 & - & - & - & - & - & - & 29 & 8.8 & 2.5 \\
\hline & Varol 2011 & 25 & 8.2 & 1.5 & - & - & - & - & - & - & 31 & 7.5 & 1.6 \\
\hline & Total or average & 532 & 6.874 & - & 421 & 7.159 & - & 448 & 6.968 & - & 805 & 7.586 & - \\
\hline \multirow[t]{6}{*}{$\operatorname{LYM}\left(10^{9} / \mathrm{L}\right)$} & Uygur 2016 & 118 & 2.3 & 1.3 & 57 & 2 & 1.2 & 53 & 1.7 & 1.4 & 61 & 1.5 & 1.2 \\
\hline & Korkmaz 2015 & 40 & 2.309 & 0.6 & 27 & 2.488 & 0.598 & 37 & 2.448 & 0.587 & 42 & 2.52 & 0.641 \\
\hline & Koseoglu 2015 & 57 & 2.98 & 0.68 & 93 & 2.68 & 0.65 & 82 & 2.61 & 0.72 & 192 & 2.28 & 0.68 \\
\hline & Yenigun 2015 & 38 & 2.37 & 0.56 & 34 & 2.86 & 0.54 & 30 & 2.34 & 0.94 & 34 & 2.07 & 0.67 \\
\hline & Song 2016 & 61 & 3.61 & 0.987 & 67 & 3.3 & 1.28 & 61 & 3 & 0.922 & 101 & 2.74 & 0.835 \\
\hline & Total or average & 314 & 2.714 & - & 278 & 2.666 & - & 263 & 2.419 & - & 430 & 2.222 & - \\
\hline \multirow[t]{6}{*}{ NLR } & Altintas 2015 & 80 & 1.52 & 0.46 & 163 & 1.54 & 0.44 & 158 & 1.63 & 0.56 & 160 & 2.37 & 0.63 \\
\hline & Uygur 2016 & 118 & 1.81 & 0.5 & 57 & 2.39 & 0.6 & 53 & 3.34 & 0.9 & 61 & 4.18 & 1.1 \\
\hline & Korkmaz 2015 & 40 & 1.8 & 0.64 & 27 & 1.78 & 0.57 & 37 & 1.57 & 0.54 & 42 & 1.61 & 0.56 \\
\hline & Koseoglu 2015 & 48 & 2.017 & 0.85 & 67 & 1.97 & 1.25 & 61 & 1.87 & 0.66 & 108 & 1.85 & 0.64 \\
\hline & Yenigun 2015 & 38 & 1.7 & 0.71 & 34 & 1.69 & 0.69 & 30 & 2.44 & 1.44 & 34 & 3.37 & 1.21 \\
\hline & Total or average & 324 & 1.769 & - & 348 & 1.874 & - & 339 & 2.17 & - & 405 & 2.676 & - \\
\hline \multirow[t]{9}{*}{ MPVfL } & Uygur 2016 & 118 & 7.9 & 1.2 & 57 & 8.1 & 0.9 & 53 & 8 & 1.1 & 61 & 8.1 & 1 \\
\hline & Karakas 2013 & 31 & 7.8 & 0.9 & 30 & 8.3 & 1.2 & 32 & 8.4 & 1.3 & 31 & 8.6 & 1.1 \\
\hline & Kurt 2013 & 20 & 8.2 & 1.1 & 15 & 8.5 & 1 & 26 & 8.3 & 1 & 37 & 8.2 & 0.9 \\
\hline & Koseoglu 2015 & 57 & 6.64 & 0.54 & 93 & 7.26 & 0.7 & 82 & 7.58 & 0.9 & 192 & 9.8 & 5.04 \\
\hline & Nena 2012 & 148 & 9.8 & 1.1 & 121 & 9.8 & 1.6 & 85 & 11.5 & 1.3 & 256 & 12.1 & 1.3 \\
\hline & Sökücü 2014 & 30 & 9.21 & 0.75 & 38 & 9.36 & 0.94 & 41 & 9.33 & 0.72 & 91 & 9.37 & 1.02 \\
\hline & Varol 2010 & 24 & 8.2 & 0.7 & - & - & - & - & - & - & 29 & 8.9 & 1 \\
\hline & Varol 2011 & 25 & 8.3 & 0.96 & - & - & - & - & - & - & 31 & 8.5 & 0.59 \\
\hline & Total or average & 453 & 8.256 & - & 354 & 8.553 & - & 319 & 8.851 & - & 728 & 9.196 & - \\
\hline \multirow[t]{7}{*}{ PDW (\%) } & Uygur2016 & 118 & 13.4 & 0.6 & 57 & 14.1 & 1.7 & 53 & 13.9 & 1.4 & 61 & 14.5 & 1.9 \\
\hline & Kurt 2013 & 20 & 13.2 & 0.5 & 15 & 14.1 & 1.6 & 26 & 13.8 & 1.2 & 37 & 14.4 & 1.8 \\
\hline & Koseoglu 2015 & 57 & 17.5 & 1.03 & 93 & 17.8 & 1.1 & 82 & 17.9 & 1.04 & 192 & 17.8 & 1.57 \\
\hline & Nena 2012 & 148 & 13.2 & 2.2 & 121 & 14.1 & 2.8 & 85 & 15 & 2.2 & 256 & 15.9 & 2.2 \\
\hline & Sokucu2014 & 30 & 15.71 & 2.12 & 38 & 16.19 & 2.34 & 41 & 15.67 & 1.91 & 91 & 15.84 & 2.88 \\
\hline & Song 2016 & 61 & 15.9 & 1.12 & 67 & 16.3 & 0.95 & 61 & 16.4 & 0.99 & 101 & 16.5 & 0.82 \\
\hline & Total or average & 434 & 14.818 & - & 391 & 15.431 & - & 348 & 15.445 & - & 738 & 15.823 & - \\
\hline \multirow[t]{4}{*}{ PLR } & Koseoglu 2015 & 57 & 87.38 & 22.9 & 93 & 95.07 & 31.3 & 82 & 97.01 & 29.1 & 192 & 126.9 & 39.4 \\
\hline & Koseoglu 2015 & 48 & 123.97 & 35.34 & 67 & 112.4 & 38.35 & 61 & 113.59 & 35.16 & 108 & 105.4 & 32.98 \\
\hline & Song 2016 & 61 & 99.5 & 42.1 & 67 & 113.8 & 45.2 & 61 & 121.3 & 62.9 & 101 & 138.6 & 59.9 \\
\hline & Total or average & 166 & 103.61 & - & 227 & 107.09 & - & 204 & 110.63 & - & 401 & 123.63 & - \\
\hline \multirow[t]{6}{*}{ RDW (\%) } & Uygur 2016 & 118 & 13.1 & 1.1 & 57 & 13.2 & 0.9 & 53 & 13.9 & 1.6 & 61 & 14.5 & 1.9 \\
\hline & Kurt 2013 & 20 & 16.5 & 0.4 & 15 & 16.6 & 0.7 & 26 & 16.6 & 0.6 & 37 & 16.8 & 0.6 \\
\hline & Koseoglu 2015 & 57 & 15.7 & 1.07 & 93 & 15.9 & 1.54 & 82 & 15.7 & 1.13 & 192 & 16.3 & 1.8 \\
\hline & $\begin{array}{c}\text { Sunnetcioglu } \\
2017\end{array}$ & 197 & 13.5 & 1.3 & 149 & 13.8 & 1.4 & 98 & 13.9 & 1.7 & 156 & 15.7 & 7.1 \\
\hline & Song 2016 & 61 & 13.5 & 1.57 & 67 & 13.3 & 1.25 & 61 & 13.5 & 1.05 & 101 & 13.3 & 0.76 \\
\hline & Total or average & 453 & 14.46 & - & 381 & 14.56 & - & 320 & 14.72 & - & 547 & 15.32 & - \\
\hline \multirow[t]{4}{*}{ НCT (\%) } & Sökücü 2014 & 30 & 43.76 & 4.24 & 38 & 44.93 & 3.89 & 41 & 44.29 & 7.27 & 91 & 44.91 & 5.87 \\
\hline & Song 2016 & 61 & 40.2 & 4.4 & 67 & 41.2 & 4.2 & 61 & 40.2 & 6.6 & 101 & 42.5 & 4.5 \\
\hline & Choi 2006 & 61 & 39.8 & 4 & - & - & - & - & - & - & 111 & 43.5 & 3.6 \\
\hline & Total or average & 152 & 41.25 & - & 105 & 43.07 & - & 102 & 42.25 & - & 303 & 43.64 & - \\
\hline
\end{tabular}

WBC, white blood cell; LYM, lymphocyte; NLR, neutrophil-to-lymphocyte ratio; PLR, platelet-to-lymphocyte ratio; HCT, hematocrit; RDW, red cell distribution width; MPV, mean platelet volume; PDW, platelet distribution width. 
Table S4 Random-effects pooled WMD for association between Hematological Parameters and severity of OSAS

\begin{tabular}{|c|c|c|c|c|}
\hline Subgroup & Severity & OSAS subjects without CVD & OSAS subjects with/without CVD & All OSAS subjects \\
\hline \multirow[t]{3}{*}{ WBC } & Mild OSAS & $0.80[-0.36,1.96](P=0.18) ; I^{2}=92 \%(P<0.00001)$ & $0.48[0.20,0.77](P=0.0008) ; I^{2}=0 \%(P=0.65)$ & $0.52[0.10,0.94](P=0.01) ; I^{2}=78 \%(P<0.0001)$ \\
\hline & Moderate OSAS & $0.49[-0.40,1.37](P=0.28) ; I^{2}=88 \%(P=0.0002)$ & $0.24[-0.54,1.03](P=0.54) ; I^{2}=83 \%(P=0.0001)$ & $0.35[-0.16,0.86](P=0.18) ; I^{2}=86 \%(P<0.00001)$ \\
\hline & Severe OSAS & $1.29[0.12,2.47](P=0.03) ; I^{2}=95 \%(P<0.00001)$ & $0.56[0.00,1.12](P=0.05) ; I^{2}=81 \%(P<0.00001)$ & $0.79[0.35,1.23](P=0.0005) ; I^{2}=87 \%(P<0.00001)$ \\
\hline \multirow[t]{3}{*}{ Neutrophil } & Mild OSAS & $0.04[-0.07,0.15](P=0.50) ; I^{2}=0 \%(P=0.35)$ & $0.78[0.52,1.03](P<0.00001) ; I^{2}=0 \%(P=0.50)$ & $0.54[0.09,1.00](P=0.02) ; I^{2}=87 \%(P<0.00001)$ \\
\hline & Moderate OSAS & $-0.10[-0.21,0.01](P=0.09) ; I^{2}=0 \%(P=0.57)$ & $1.00[-0.02,2.01](P=0.05) ; I^{2}=94 \%(P<0.00001)$ & $0.53[-0.30,1.35](P=0.21) ; I^{2}=97 \%(P<0.00001)$ \\
\hline & Severe OSAS & $-0.30[-0.40,-0.20] ;(P<0.00001) I^{2}=0 \%(P=0.44)$ & $1.93[0.43,3.42](P=0.01) ; I^{2}=95 \%(P<0.00001)$ & $1.03[-0.04,2.11](P=0.06) ; I^{2}=98 \%(P<0.00001)$ \\
\hline \multirow[t]{3}{*}{ Lymphocyte } & Mild OSAS & $0.34[0.04,0.65](P=0.03) ; I^{2}=60 \%(P=0.12)$ & $-0.30[-0.47,-0.13](P=0.0006) ; I^{2}=0 \%(P=1.00)$ & $-0.04[-0.38,0.31](P=0.84) ; I^{2}=85 \%(P<0.0001)$ \\
\hline & Moderate OSAS & $0.08[-0.13,0.30](P=0.45) ; I^{2}=0 \%(P=0.48)$ & $-0.47[-0.65,-0.30](P<0.00001) ; I^{2}=0 \%(P=0.43)$ & $-0.28[-0.58,0.02](P=0.06) I^{2}=77 \%(P=0.002)$ \\
\hline & Severe OSAS & $-\left.0.04[-0.54,0.46](P=0.87)\right|^{2}=85 \%(P=0.01)$ & $-0.76[-0.91,-0.61](P<0.00001) I^{2}=0 \%(P=0.63)$ & $-0.49[-0.88,-0.09](P=0.02) ; I^{2}=90 \%(P<0.00001)$ \\
\hline \multirow[t]{3}{*}{ NLR } & Mild OSAS & $0.01[-0.10,0.12](P=0.87) ; I^{2}=0 \%(P=0.93)$ & $0.30[-0.28,0.88](P=0.31) ; I^{2}=90 \%(P=0.002)$ & $0.12[-0.16,0.40](P=0.40) ; I^{2}=86 \%(P<0.00001)$ \\
\hline & Moderate OSAS & $-0.06[-0.30,0.17](P=0.59) ; I^{2}=69 \%(P=0.04)$ & $1.18[0.41,1.95](P=0.003) ; l^{2}=84 \%(P=0.01)$ & $0.39[-0.23,1.02](P=0.22) ; I^{2}=97 \%(P<0.00001)$ \\
\hline & Severe OSAS & $0.17[-0.60,0.94](P=0.66) ; I^{2}=97 \%(P<0.00001)$ & $2.04[1.36,2.73](P<0.00001) ; I^{2}=84 \%(P=0.01)$ & $0.90[0.04,1.76](P=0.04) ; I^{2}=98 \%(P<0.00001)$ \\
\hline \multirow[t]{3}{*}{ MPV } & Mild OSAS & $0.21[-0.28,0.69](P=0.40) ; I^{2}=59 \%(P=0.12)$ & $0.35[0.07,0.63](P=0.01) ; I^{2}=60 \%(P=0.06)$ & $0.30[0.06,0.55](P=0.02) ; I^{2}=62 \%(P=0.02)$ \\
\hline & Moderate OSAS & $1.17[0.10,2.25](P=0.03) ; l^{2}=91 \%(P=0.0008)$ & $0.34[-0.17,0.85](P=0.19) ; I^{2}=83 \%(P<0.0001)$ & $0.61[0.07,1.15](P=0.03) ; I^{2}=92 \%(P<0.00001)$ \\
\hline & Severe OSAS & $1.57[0.10,3.04](P=0.04) ; I^{2}=96 \%(P<0.00001)$ & $0.69[0.05,1.33](P=0.04) ; I^{2}=92 \%(P<0.00001)$ & $0.93[0.13,1.72](P=0.02) ; I^{2}=97 \%(P<0.00001)$ \\
\hline \multirow[t]{3}{*}{ PDW } & Mild OSAS & $0.90[0.29,1.51](P=0.004)$ & $0.46[0.25,0.67](P<0.0001) ; I^{2}=0 \%(P=0.55)$ & $0.51[0.31,0.70](P<0.00001) ; l^{2}=0 \%(P=0.44)$ \\
\hline & Moderate OSAS & $1.80[1.21,2.39](P<0.00001)$ & $0.46[0.27,0.66](P<0.00001) ; I^{2}=0 \%(P=0.82)$ & $0.64[0.26,1.03](P=0.001) ; I^{2}=74 \%(P=0.02)$ \\
\hline & Severe OSAS & $2.70[2.25,3.15](P<0.00001)$ & $0.68[0.32,1.05](P=0.0002) ; I^{2}=65 \%(P=0.02)$ & $1.02[0.26,1.79](P=0.008) ; I^{2}=94 \%(P<0.00001)$ \\
\hline \multirow[t]{3}{*}{ PLR } & Mild OSAS & $-11.57[-25.14,2.00](P=0.09)$ & $9.34[1.79,16.88](P=0.02) ; I^{2}=0 \%(P=0.46)$ & $3.53[-10.25,17.31](P=0.62) ; I^{2}=73 \%(P=0.02)$ \\
\hline & Moderate OSAS & $-10.38[-23.71,2.95](P=0.13)$ & $12.66[2.35,22.97](P=0.02) ; I^{2}=23 \%(P=0.25)$ & $6.21[-10.08,22.49](P=0.46) ; I^{2}=78 \%(P=0.01)$ \\
\hline & Severe OSAS & $-18.57[-30.34,-6.80](P=0.002)$ & $39.43[32.19,46.67](P<0.00001) ; I^{2}=0 \%(P=0.96)$ & $19.97[-18.77,58.71](P=0.31) ; I^{2}=97 \%(P<0.00001)$ \\
\hline \multirow[t]{3}{*}{ RDW } & Mild OSAS & - & $0.14[-0.02,0.31](P=0.08) ; I^{2}=0(P=0.53)$ & - \\
\hline & Moderate OSAS & - & $0.24[-0.03,0.51](P=0.08) ; I^{2}=58(P=0.05)$ & - \\
\hline & Severe OSAS & - & $0.72[0.15,1.29](P=0.01) ; I^{2}=88 \%(P<0.00001)$ & - \\
\hline \multirow[t]{3}{*}{ HCT } & Mild OSAS & - & $1.06[-0.12,2.25](P=0.08) ; I^{2}=0 \%(P=0.89)$ & - \\
\hline & Moderate OSAS & - & $0.19[-1.41,1.79](P=0.82) ; I^{2}=0 \%(P=0.76)$ & - \\
\hline & Severe OSAS & - & $2.53[1.12,3.94](P=0.0004) ; I^{2}=63 \%(P=0.07)$ & - \\
\hline
\end{tabular}

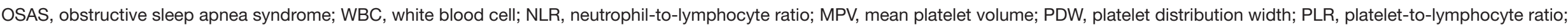
RDW, red cell distribution width; HCT, hematocrit. 
Table S5 Publication bias of each subgroup using Stata SE12.0

\begin{tabular}{lccc}
\hline Subgroup & Included studies & Begg's test & Egger's test \\
\hline WBC & 11 & 0.081 & 0.082 \\
Lymphocyte & 5 & 0.480 & 0.589 \\
NLR & 5 & 0.322 & 0.883 \\
MPV & 8 & 0.651 & 0.121 \\
PDW & 6 & 0.129 & 0.079 \\
PLR & 3 & 1.000 & 0.820 \\
RDW & 5 & 0.480 & 0.592 \\
HCT & 3 & 0.296 & 0.217 \\
\hline
\end{tabular}

All studies were without publication bias $(P>0.05)$. WBC, white blood cell; NLR, neutrophil-to-lymphocyte ratio; MPV, mean platelet volume; PDW, platelet distribution width; PLR, platelet-to-lymphocyte ratio; RDW, red cell distribution width; HCT, hematocrit. 